\title{
ORIGINAL
}

\section{Inhibition of GHRH aggravated acetaminophen-induced acute mice liver injury through GH/IGF-I axis}

\author{
Tao Wang, Jie Hai, Xuehui Chen, Hua Peng, He Zhang, Lake Li and Qinggui Zhang \\ First affiliated hospital, Xinxiang Medical University, Henan, China
}

\begin{abstract}
The aim of the current study is to investigate the effects of growth hormone releasing hormone (GHRH) antagonist on acetaminophen (APAP)-induced acute liver injury in mice. Healthy C57/B6L mice were orally treated with $200 \mathrm{mg} / \mathrm{kg}$ APAP with or without a 30-min pre-treatment with $300 \mu \mathrm{g} / \mathrm{kg}$ GHRH antagonist MZ-5-156. After 12 hours, serum, plasma, and liver samples from each mouse were collected for analyses. Our results showed that twelve-hour treatment with APAP caused obvious liver injury, elevated serum alanine aminotransferase (ALT) and aspartate aminotransferase (AST) levels, increased oxidative stress, reduced expressions of antioxidant enzymes, accumulated expression of pro-inflammatory cytokines, and increased circulating levels of growth hormone (GH) and insulin-like growth factor-I (IGF-I). Pre-treatment with MZ-5-156 aggravated liver injury, further increased serum ALT and AST levels, exacerbated oxidative stress and inflammation induced by APAP. Treatment of MZ-5-156 also blocked the phosphorylation form and total form of Janus kinase 2 (JAK2) and signal transducer and activator of transcription 5 (STAT5). Treatment of GHRH super-agonist JI-38 immediately after MZ-5-156 treatment partly reversed the liver injury caused by APAP and MZ-5-156. In conclusion, GHRH plays essential protective role in APAP-induced acute liver injury in vivo. The protective properties of GHRH are partially through GH/IGF-I axis and JAK/STAT pathway.
\end{abstract}

Key words: GHRH antagonist, Acetaminophen, Liver injury, GH/IGF-I axis

DRUG-induced acute liver injury is an important cause of acute liver failure. In the United States, about 2,000 cases of acute liver failure occur annually. Half of the cases are from abuse or overuse of drugs [1]. Acetaminophen (also known as paracetamol, $\mathrm{N}$-acetylp-aminophenol, APAP) is a well-documented over-thecounter antipyretic and analgesic drug mainly used for the relief of headache and other kinds of aches. It is also a well-characterized hepatotoxin with dose-dependent manner. When ingested in excessive dose, APAP can induce life-threatening acute hepatic injury [2]. After ingestion, APAP is metabolized by the cytochrome P450 system to form a highly reactive intermediate metabolite N-acetyl-pbenzoquinone-imine (NAPQI) [3]. Under normal circumstances, NAPQI will be eliminated by conjugation with glutathione (GSH) to form mercapturic acid which will be excreted into the urine [4]. Excessive administration of APAP may saturate the glucuronidation pathway, leading to structural and

Submitted Nov. 24, 2011; Accepted Mar. 27, 2012 as EJ11-0356 Released online in J-STAGE as advance publication Apr. 26, 2012 Correspondence to: Qinggui Zhang, Department of Endocrinology, First affiliated hospital, Xinxiang Medical University, Henan, China. E-mail: zqgzzz@163.com functional dysfunctions of the cell induced by accumulated NAPQI [5]. Moreover, depletion of intracellular GSH after overdose APAP ingestion renders liver cells highly vulnerable to oxidative stress, inflammation, and necrosis [6]. The oxidative stress formed by APAP overdose is initiated by cellular superoxide formation through the uncoupling of cytochrome P450 enzymes to other enzymes and mitochondria or the activation of NAPDH oxidase [7, 8]. Since GSH is the cofactor for glutathione peroxidase (GPx) detoxification of peroxides, depletion of GSH also leads to increased intracellular levels of peroxides [5].

Growth hormone releasing hormone (GHRH) is the releasing hormone of growth hormone $(\mathrm{GH})$ through the binding of GHRH receptor in the anterior pituitary. Dysregulation of GHRH secretion and action induces abnormalities in body growth, protein regulation, bone growth, and metabolism [9]. GHRH is involved in the pathogenesis of a large number of cancers, including ovarian, breast, lung, prostatic, colorectal, and gastroenteropancreatic cancers, as these tumors are the most important non-hypothalamic source of GHRH [10]. In vivo studies showed that antagonist of GHRH (e.g. MZ-5$156)$ inhibited the growth of human prostate cancer [11, 
12], breast cancer [11], ovarian cancer [13], and pancreatic cancer [14]. Therefore, applying GHRH antagonist in the treatment of cancer has become a promising direction for cancer therapy. However, the role of GHRH in acute liver injury largely remains unclear. In the current study, we investigated the effects of GHRH antagonist MZ-5-156 and GHRH agonist JI-38 on APAP-induced acute liver injury in a mice model. Inhibition of GHRH exacerbated the oxidative stress and necro-inflammation induced by APAP partly though the GH/IGF-I axis and Janus kinase 2 (JAK2)/signal transducer and activator of transcription 5 (STAT5) pathway.

\section{Materials and Methods}

\section{Animals and treatments}

Fifty healthy male C57/B6L mice ( 25 g, 8-9 weeks old) were purchased from animal center of Xinxiang Medical University. Then mice were housed in a well temperature- and humidity-controlled environment for 1 week before experiment. Mice were divided into five groups $(\mathrm{n}=10)$. Vehicle mice were freely accessed with regular chow and tap water. APAP treated mice were given oral APAP (200 mg/kg) with or without a 30-min pre-treatment of $300 \mu \mathrm{g} / \mathrm{kg}$ GHRH antagonist MZ-5156 (i.v. injection). Vehicle-treated MZ-5-156 mice were also received the pre-treatment of MZ-5-156 as the control. To further test the effect of GHRH during liver injury, we treat the fifth group of mice with MZ-5156 and GHRH agonist JI-38 (50 $\mu \mathrm{g} / \mathrm{kg}$, i.v. injection) before the APAP treatment. After 12 hours, mice were anesthetized and then sacrificed. The anesthesia agent was the mixture of ketamine $(100 \mathrm{mg} / \mathrm{kg}$ ) and xylazine $(10 \mathrm{mg} / \mathrm{kg})$. The pre-treatment period and dosage of MZ-5-156 and JI-38 were optimized by previous studies $[15,16]$. Serum and plasma samples were obtained from whole blood by centrifugation at 3,000 rpm for 15 min. Liver sample from each mouse was collected for histological examination and molecular measurement. The entire animal experiment has been approved by the animal center of Xinxiang Medical University.

\section{Biochemical assays}

The serum alanine aminotransferase (ALT) and aspartate aminotransferase (AST) levels of mice were detected by corresponding detection kits (Liaoning Taike Medical Science Company, China) according to the manufacturer's protocols respectively.

\section{Histological assessment}

Liver tissue sample from each mouse were fixed in $10 \%$ phosphate-buffered formalin, and then embedded in paraffin blocks. Five-micrometer tissue sections were cut and stained with hematoxylin and eosin (H\&E) for histological analysis under light microscope (Nikon, Japan).

\section{Determining lipid peroxidation in liver tissue}

Liver tissue was homogenized in Tris-HCl buffer (20 $\mathrm{mM}$ [pH 7.4]) and then centrifuged at $2500 \times \mathrm{g}$ at $4{ }^{\circ} \mathrm{C}$ for $10 \mathrm{~min}$. Two hundred microliters of supernatant was analyzed for malondialdehyde (MDA) levels using a kit (Bioxytech MDA-586; Oxis Research, Foster City, CA) and the spectrophotometer was read at $586 \mathrm{~nm}$.

\section{Measurement of CAT and SOD activity}

Twenty microliters of supernatant of homogenized liver tissue was analyzed for super oxide dismutase (SOD) and catalase (CAT) activity by using appropriate kits (CAT kit: Cayman Chemical; SOD kit: SigmaAldrich, Buchs, Switzerland).

\section{RNA extraction and quantitative PCR measurement}

Total RNA of each mouse was extracted from the liver sample using RNeasy Mini Kit (Qiagen, Valencia, CA) and then quantified with the spectrophotometer (Beckman Coulter, Fullerton, CA). The reverse-transcription of total RNA was performed by SuperScriptTM First-Strand Synthesis System (Invitrogen, Calsbad, CA). The mRNA expression levels of tumor necrosis factor-alpha (TNF- $\alpha$ ), interleukin $1 \beta$ (IL-1 $\beta$ ), and GPx1 were measured by quantitative real-time PCR conducted in ABI Prism 7300 machine with ABI SYBR green system (Applied Biosystems, Forster City, CA). Primer sequences are: (1) TNF- $\alpha$ : forward: 5'-CAGGCGGTGCCTATGTCTC-3'; reverse: 5'-CGATCACCCCGAAGTTCAGTAG-3'; (2) IL-13: forward: 5'- GAAATGCCACCTTTTGACAGTG-3'; reverse: 5'- CTGGATGCTCTCATCAGGACA-3'; (3) GPx1: forward: 5'- CCACCGTGTATGCCTTCTCC-3'; reverse: 5'- AGAGAGACGCGACATTCTCAAT-3'. Parallel amplification of $\beta$-actin was used as the internal control. Fold change of each gene was calculated by using the comparative Ct method. All quantitative PCR procedures, including the design of primers, validation of PCR environment, and quantification methods were performed according the MIQE guideline [17]. 


\section{Western blot analysis}

To determine the role of JAK2 and STAT5 in GHRH inhibition, specific antibodies against the phosphorylated and normal forms of JAK2 and STAT5 (Cell Signaling, Danvers, MA) were used in Western blotting of mice liver samples. Antibody of CYP2E1 (Millipore, Billerica, MA) was also applied to characterize the expressional change of CYP2E1. Liver samples were homogenized in lysis buffer $(150 \mathrm{mM} \mathrm{NaCl}, 10$ mM HEPES, $\mathrm{pH} 7.9,1 \mathrm{mM}$ EDTA, 0.6\% NP-40, 0.5 $\mathrm{mM}$ PMSF, $1 \mu \mathrm{g} / \mathrm{mL}$ leupeptin, $1 \mu \mathrm{g} / \mathrm{mL}$ aprotonin, and $10 \mu \mathrm{g} / \mathrm{mL}$ trypsin inhibitor). Samples were then sonicated and incubated for 30 minutes on ice. Debris was removed by centrifugation at 10,000 rpm. Protein concentrations of each sample were determined in order to calculate the loading amount. Samples were separated in a denaturing $10 \%$ polyacrylimide gel and transferred to a $0.1 \mu \mathrm{m}$ pore nitrocellulose membrane. Nonspecific binding sites were blocked with tris-buffered saline (TBS; $40 \mathrm{mM}$ Tris, $\mathrm{pH}$ 7.6, $300 \mathrm{mM} \mathrm{NaCl}$ ) containing $5 \%$ nonfat dry milk for 1 hour at room temperature. Membranes were then incubated with appropriate primary antibodies in TBS with $0.1 \%$ Tween 20 (TBST). Membranes were washed and incubated with secondary antibodies conjugated to horseradish peroxidase to show the result bands with ECL buffer (GE Healthcare, UK). Parallel blotting of $\beta$-actin was used as internal control.

\section{Measurement of circulating GH and IGF-I}

To analyze the circulating levels of GHandIGF-I, commercial kits (GH: Millipore; IGH-I: Immunodiagnostic Systems, Fountain Hills, AZ) were used according to manufacturer's instructions in the plasma samples.

\section{Statistical analysis}

All values were expressed in the form of mean \pm S.D. Statistical comparison between groups was done using variance (ANOVA) and post hoc LSD tests. A $p<0.05$ was considered to be statistically significant (SPSS version 17.0, IBM Corporation, Armonk, New York).

\section{Results}

\section{Pre-treatment with MZ-5-156 aggravated the liver injury induced by APAP}

In control mice, there was no abnormal morphological change could be observed under light microscope (Fig. 1A). Twelve-hour treatment of APAP induced classical damage in the mice liver, as demonstrated by necrosis and phagocyte filtration. The histological changes were more obvious around liver centrilobular veins (Fig. 1B). Pre-treatment with MZ-5-156 caused slight liver damage in vehicle-MZ-5-156 mice (Fig. 1C). Animals treated with MZ-5-156 followed by APAP showed worst degree of histological changes (Fig. 1D). Co-treatment of JI-38, the super-agonist of GHRH, significantly improved the histology of the liver (Fig. 1E). Serum levels of ALT and AST were consistent with the histological results. When compared with the control level, elevated serum ALT and AST levels by APAP treatment were further increased by the pre-treatment of MZ-5-156. Vehicle-treated MZ-5-156 mice also showed increases of both ALT and AST levels in the serum compared to those in control group, although the increases were not significant. Co-treatment with JI-38 partly reduced the levels of ALT and AST (Table 1).

\section{MZ-5-156 pre-treatment exacerbated oxidative stress induced by APAP \\ After APAP treatment, protein expression of CYP2E1 was significantly elevated by approximately 2.7 -fold. Pre-treatment with MZ-5-156 further increased such elevation (Fig. 2A). The level of serum MDA exhib-}

Table 1 Effects of MZ-5-156 and APAP on serum ALT and AST levels

\begin{tabular}{lcc}
\hline Group & ALT $(\mathrm{IU} / \mathrm{L})^{\mathrm{a}}$ & AST $(\mathrm{IU} / \mathrm{L})^{\mathrm{a}}$ \\
\hline Control & $59.6 \pm 7.7$ & $198.1 \pm 20.5$ \\
APAP & $1230.5 \pm 111.4^{*}$ & $3470.9 \pm 355.8^{*}$ \\
MZ-5-156 & $77.5 \pm 9.1$ & $237.4 \pm 24.4$ \\
MZ-5-156+APAP & $2502 \pm 211.8^{\#}$ & $4982.0 \pm 515.7^{\#}$ \\
MZ-5-156+JI-38+APAP & $1058 \pm 156.6^{*}$ & $2137 \pm 246.0^{*}$ \\
\hline
\end{tabular}

${ }^{a}$ Values are means \pm S.D., $\mathrm{n}=10 ; *$ Statistical significance: $p<0.05$, compared with control group; \# Statistical significance: $p<0.05$, compared with control and APAP groups 


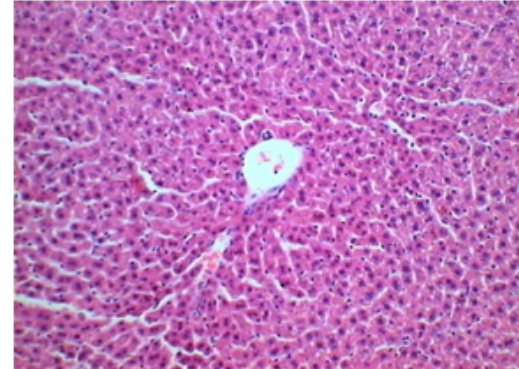

Control

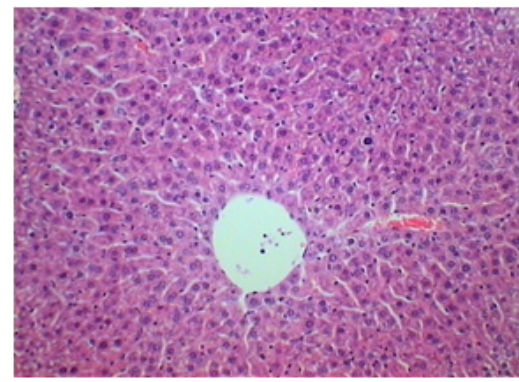

MZ-5-156

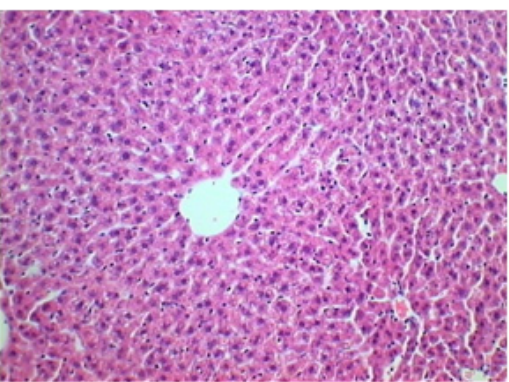

MZ-5-156+JI-38+APAP

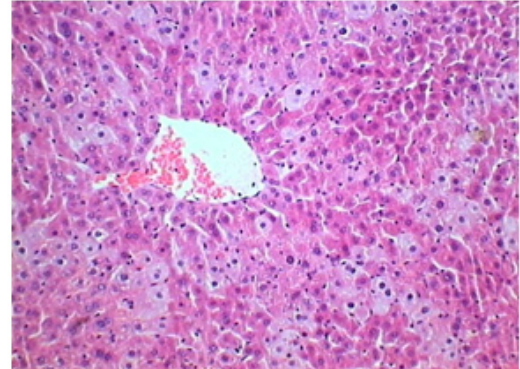

APAP

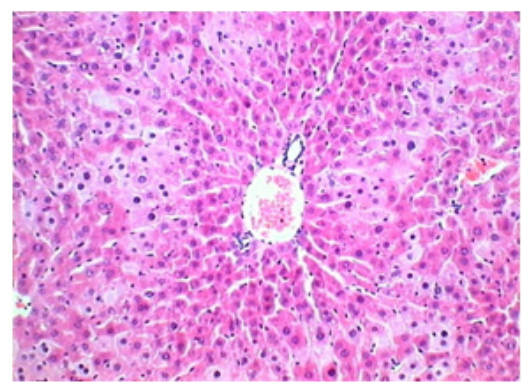

MZ-5-156+APAP

Fig. 1 Representative results of hematoxylin and eosin (H\&E) staining of mice liver tissues from each group. Mice were treated with $200 \mathrm{mg} / \mathrm{kg}$ acetaminophen (APAP) with or without a pre-treatment of $300 \mu \mathrm{g} / \mathrm{kg}$ growth hormone releasing hormone (GHRH) antagonist MZ-5-156 and/or agonist JI-38. Magnification: 200x.

ited similar expressional change with that of CYP2E1 (Fig. 2B). As expected, treatment of APAP significantly down-regulated the mRNA expression level of SOD, CAT, and GPx1. Mice pre-treated with MZ-5-156 followed by APAP treatment showed lower expression of CAT and GPx1 than those of the APAP-treated mice (Fig. 2C-2E). Co-treatment of MZ-5-156 and JI-38 prior to APAP administration counteracted the effects of APAP and MZ-5-156 (Fig. 2).

\section{APAP-induced hepatic inflammation was aggravated by MZ-5-156 pre-treatment}

TNF- $\alpha$ and IL- $1 \beta$ are important mediators of inflammatory response in the liver. After APAP treatment, mRNA expressions of TNF- $\alpha$ and IL- $1 \beta$ were remark- ably up-regulated by 5.5 folds and 2.1 folds, respectively. Pre-treatment with MZ-5-156 further elevated the expressions of these two genes to approximately 7.3 folds and 3.2 fold. Vehicle-treated MZ-5-156 also showed slightly elevated expression of TNF- $\alpha$ but no significant change of IL-1 $\beta$ (Fig. 3). Pre-treatment with JI-38 partly reversed the effects of APAP and MZ-5156 on the cytokines.

\section{Effects of MZ-5-156 on APAP-treated mice were through inhibition of JAK2 and STAT5}

The JAK/STAT pathway is an essential signal transduction component in GH-mediated physiological events [19]. To investigate the role of JAK2 and STAT5 on MZ-5-156 and APAP induced hepatotoxic- 
A

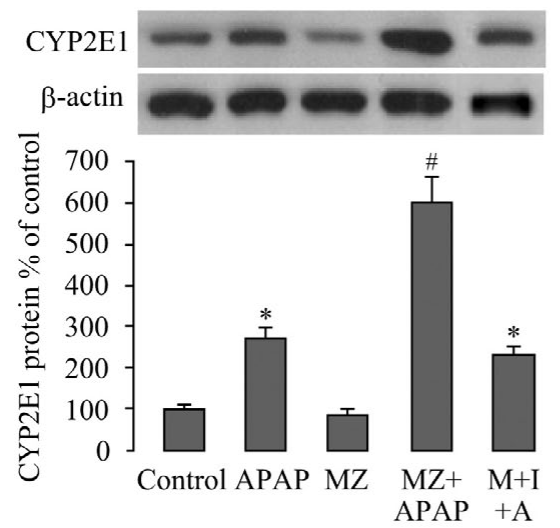

C

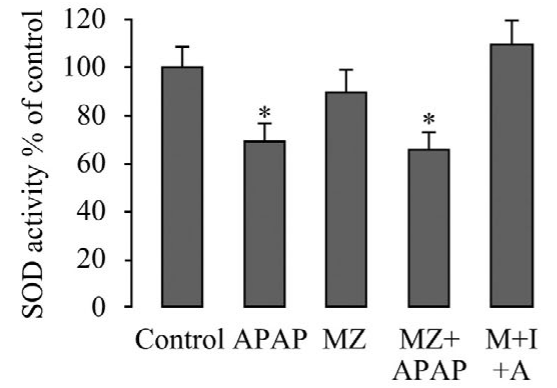

$\mathbf{E}$

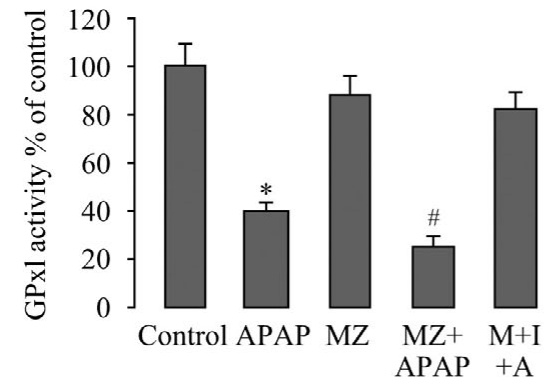

B
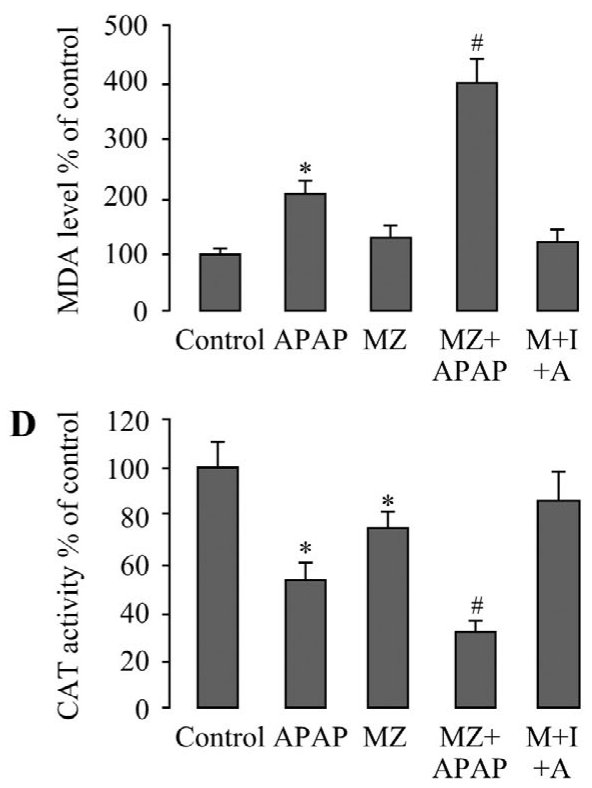

Fig. 2 Levels of (A) CYP2E1 protein, (B) MDA formation, (C) SOD activity, (D) CAT activity, and (E) GPx1 mRNA expression from each group of mice. Mice were treated with $200 \mathrm{mg} / \mathrm{kg}$ acetaminophen (APAP) with or without a pre-treatment of $300 \mu \mathrm{g} / \mathrm{kg}$ growth hormone releasing hormone (GHRH) antagonist MZ-5-156 and/or agonist JI-38. Mark "**" stands for a statistically significant change compared to control group $(p<0.05)$. Mark "\#" stands for a statistically significant change compared to APAP group $(p<0.05)$. Data presented are expressed as Mean \pm S.D. $(\mathrm{n}=10)$. MZ, MZ-5-156; MZ+APAP, MZ-5-156 and acetaminophen co-treatment; M+I+A, MZ-5-156, JI-38 and acetaminophen co-treatment.
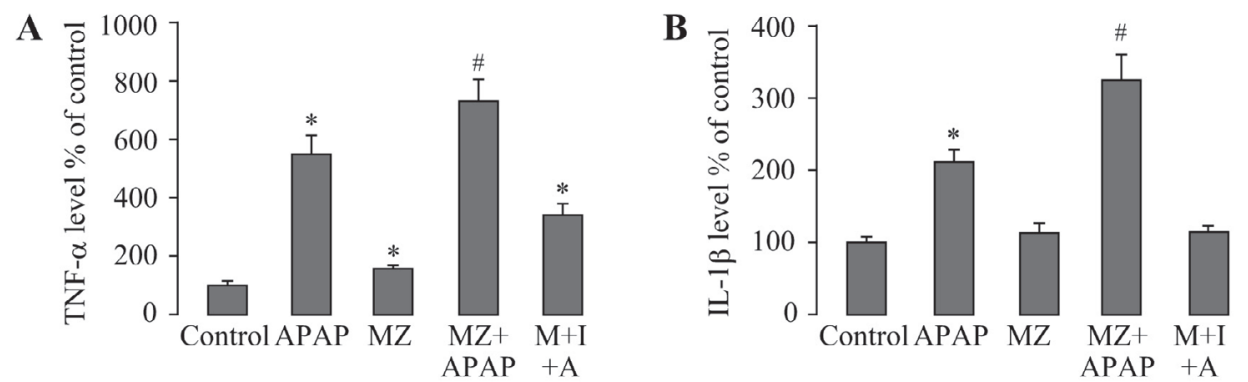

Fig. 3 Hepatic expressional changes of (A) TNF- $\alpha$ and (B) IL-1 $\beta$ from each group of mice. Mice were treated with $200 \mathrm{mg} / \mathrm{kg}$ acetaminophen (APAP) with or without a pre-treatment of $300 \mu \mathrm{g} / \mathrm{kg}$ growth hormone releasing hormone (GHRH) antagonist MZ-5-156. Mark "**" stands for a statistically significant change compared to control group $(p<0.05)$. Mark " "\#" stands for a statistically significant change compared to APAP group $(p<0.05)$. Data presented are expressed as Mean \pm S.D. $(\mathrm{n}=10)$. MZ, MZ-5-156; MZ+APAP, MZ-5-156 and acetaminophen co-treatment; M+I+A, MZ-5-156, JI-38 and acetaminophen co-treatment. 
ity, both phosphorylation form and total protein expression of these proteins were measured by Western blot. After APAP intoxication, phosphorylation of JAK2 and STAT5 was more obvious than that in control group. However, total protein expressions of JAK2 and STAT5 did not show significant change. Treatment of MZ-5156, both in APAP-treated and vehicle mice, dramatically inhibited the phosphorylation and basal expressions of JAK2 and STAT5 (Fig. 4). JI-38 restored both phosphorylation and total protein levels of JAK2 and STAT5 in the liver.

\section{Pre-treatment with MZ-5-156 reduced circulating levels of GH and IGF-I}

To investigate the possible involvements of GH and IGF-I, circulating levels of these hormones were measured in the plasma. Treatment of APAP slightly increased the circulating levels of both GH and IGF-I. However, pretreatments with MZ-5-156 dramatically reduced the circulating GH level and moderately decreased the IGF-I level in both vehicle- and APAP-treated mice (Table 2). As a super-agonist of GHRH, treatment of JI-38 strongly restored the level of GH and IGF-I.

\section{Discussion}

Antagonists of GHRH have been found to suppress the in vivo growth of a large number of experimental cancers, such as prostatic, mammary, ovarian, and lung carcinomas. The inhibitory effects of GHRH antagonists are partly from their inhibition of GHRH induced GH release from the pituitary, which in turn reduces the levels of hepatic and circulating IGF-I [10]. Another mechanism that contributes to the antitumor property of GHRH antagonism is based on the suppression of secreted IGF-I and IGF-II from the tumors [19]. Antagonists GHRH also exert antioxidative effect in tumors through activating p53, leading to the antioxidant defense of the cell [20,21]. However, in this study, pre-treatment with GHRH antagonist MZ-5-156 aggravated the acute hepatotoxicity, including histological change, oxidative stress, and inflammation which were induced by APAP intoxication, suggesting a protective role of GHRH in toxin-induced acute liver injury. The protection of GHRH is partly through the GH/IGF-I axis and the JAK2/STAT5 pathway. Application of the super-agonist of GHRH, JI-38, further confirmed the essential roles of GHRH in acute liver injury. However, since serum levels of GH
A
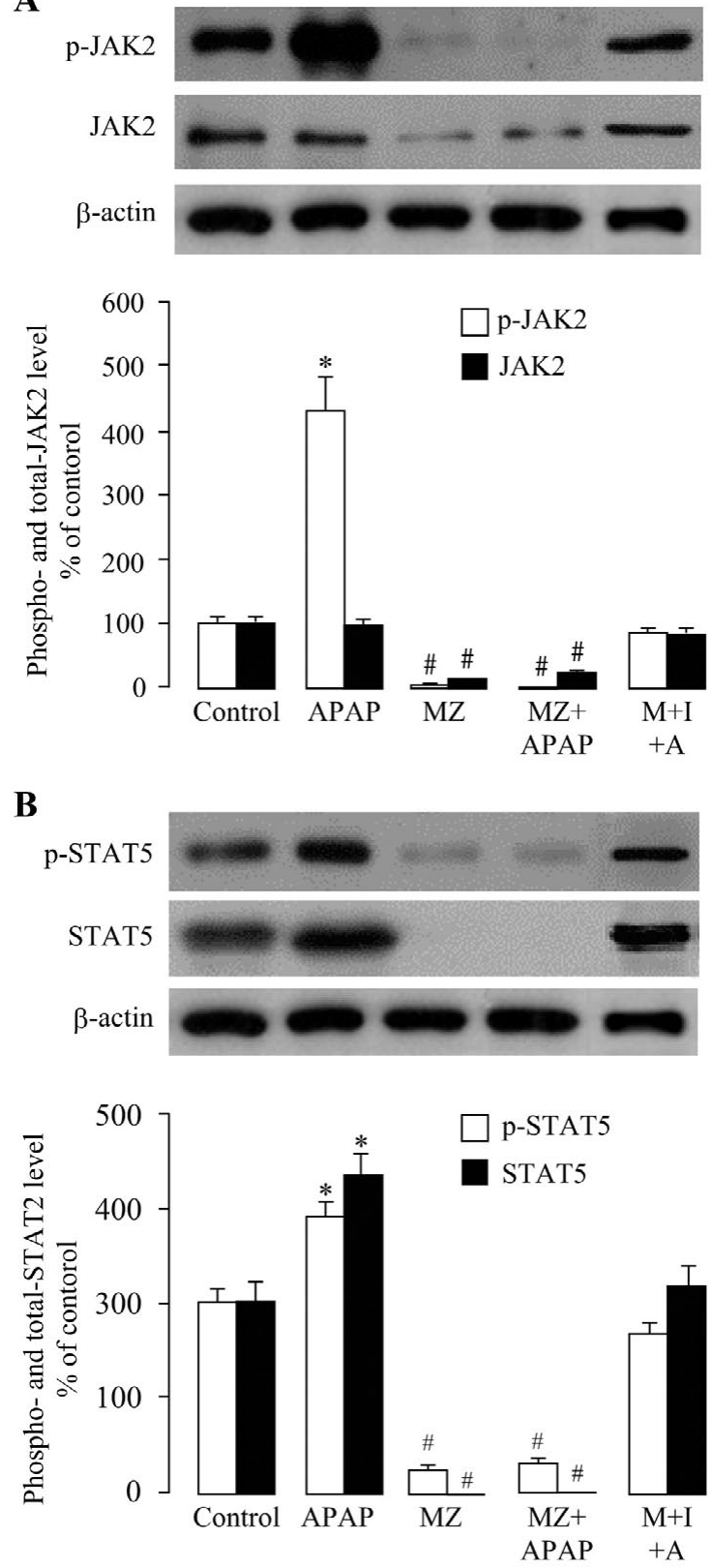

Fig. 4 Representative results of phosphorylation form and total protein expression of (A) JAK2 and (B) STAT5 from each group of mice. Mice were treated with $200 \mathrm{mg} / \mathrm{kg}$ acetaminophen (APAP) with or without a pre-treatment of $300 \mu \mathrm{g} / \mathrm{kg}$ growth hormone releasing hormone (GHRH) antagonist MZ-5-156. $\beta$-actin was blotted as parallel control. Quantitative date showed the ratio between each form of gene against control. Mark “*” stands for a statistically significant change compared to control group $(p<0.05)$. Mark “\#” stands for a statistically significant change compared to APAP group $(p<0.05)$. Data presented are expressed as Mean \pm S.D. $(n=6)$. MZ, MZ5-156; MZ+APAP, MZ-5-156 and acetaminophen cotreatment; $\mathrm{M}+\mathrm{I}+\mathrm{A}, \mathrm{MZ}-5-156$, JI-38 and acetaminophen co-treatment. 
Table 2 Effects of MZ-5-156 and APAP on circulating levels of GH and IGF-I

\begin{tabular}{lcc}
\hline Group & GH $(\mathrm{ng} / \mathrm{mL})^{\mathrm{a}}$ & IGF-I $(\mathrm{ng} / \mathrm{mL})^{\mathrm{a}}$ \\
\hline Control & $73.5 \pm 6.9$ & $211.4 \pm 18.6$ \\
APAP & $94.5 \pm 6.7^{*}$ & $224.1 \pm 20.1^{*}$ \\
MZ-5-156 & $12.8 \pm 3.0^{\#}$ & $68.4 \pm 7.5^{\#}$ \\
MZ-5-156+APAP & $15.4 \pm 1.7^{\#}$ & $75.5 \pm 8.2^{\#}$ \\
MZ-5-156+JI-38+APAP & $127.7 \pm 11.1^{*}$ & $202 \pm 19.8^{*}$ \\
${ }^{a}$ Values are means \pm S.D., $\mathrm{n}=10 ;{ }^{*}$ Statistical significance: $p<0.05$, compared \\
with control group; ${ }^{\#}$ Statistical significance: $p<0.05$, compared with control and \\
APAP groups
\end{tabular}

and IGF-1 were completely reversed by GHRH agonist, whereas up-regulated phosphorylated JAK2 and total STAT5 induced by APAP were partially reversed by GHRH agonist, it is possible that other mechanisms than GH-IGF-1 axis may take part in APAP-induced hepatotoxicity. The limitation of this study is whether MZ-5-156 has direct actions on the liver or not is not clear. As a potent antagonist of GHRH, it probably aggravated liver injury through the pituitary-liver axis by reducing circulating and hepatic expression levels of GH and IGF-I. Further studies are needed to characterize its effect on the liver and the direct relationship between MZ-5-156 and GH.

A recent report demonstrated that GHRH agonist had a protective property after an acute myocardial infarction in vivo [22]. Since there was an expression of GHRH receptor in the cardiomyocytes, the protective effects of GHRH agonist after myocardial infarction was probably not through the GH/IGH-I axis. In addition, circulating levels of GH and IGF-I were not elevated by GHRH agonist treatment, further suggested the independence of GHRH effect from GH/ IGF-I actions. Our study also found that GHRH was important for the protection against APAP induced hepatotoxicity by showing that inhibition of GHRH in the liver aggravated the acute injury caused by APAP. However, since the phosphorylation form and total protein expressions of JAK2 and STAT5 were significantly reduced by GHRH antagonist, it is reasonable to postulate that GH participated in this process. The change of circulating levels of GH and IGF-I further proved the involvement of GH/IGF-I axis in the protective effect of GHRH against APAP induced toxicity (Table 2). It is interesting that administration of GHRH agonist JI-38 dramatically restored the circulating levels of GH and IGF-I, solidly proved the involvement of GH/IGF-I axis. GH has been shown to enhance the immune system and to reduce the acute inflammatory responses after sepsis, trauma, major operation, and thermal injury [23-27]. The essential protective roles of GH against acute liver injury have also been demonstrated in animal models. For example, cardiopulmonary bypass induced acute hepatic inflammation, oxidative stress, and apoptosis were reversed by cotreatment of recombinant human GH [28]. In the current study, the aggravated acute liver injury induced by MZ-5-156 and APAP co-treatments was primarily originated from the inhibition of GH release from the pituitary. However, we cannot exclude the possible autocrine and paracrine actions of GHRH in the liver, which is independent of the GH/IGF-I axis. In addition, previous studies have demonstrated that inhibition of GH (by using its antagonist G120K-PEG) inhibited the phosphorylation of JAK2 and following signaling pathways in mice. Administration of exogenous GH could partly reverse such phenomena [29,30]. Another report showed that administrations of exogenous GHRH and GHRH antagonist (JMR-132) activated and suppressed the JAK2/STAT3 pathway (both phosphorylated and total forms of JAK2 and STAT3) in vitro, respectively [31]. So we believe that the effects of MZ-5-156 could be explained by the reduced plasma GH levels. Further investigations are needed to address this possibility. It should be noted that, according to a previous report, usage of ketamine and xylazine in anesthesia increased the plasma level of GH in rat [32]. However, in the current study, MZ-5-156 significantly reduced the level of $\mathrm{GH}$, which exhibited more potent influence to the $\mathrm{GH}$ level than ketamine and xylazine could.

CYP2E1 is the key mediator of APAP-induced hepatotoxicity. Knockout of CYP2E1 prevented APAPinduced oxidative stress and injury through diminishing the production of the toxic electrophile, NAPQI [33]. Moreover, overexpression of CYP2E1 increased 
the sensitivity of liver cells to APAP-induced toxicity in vitro [34]. In this study, up-regulated protein expression of CYP2E1 was further increased by the pre-treatment with MZ-5-156 but decreased through the addition of JI-38, suggesting the essential role of GHRH in the control of oxidative stress. Considering that inhibition of GHRH, GH, and IGF-I in the current study reduced the antioxidant system in the liver, it is reasonable to postulate the antioxidative role of GHRH/GH/IGF-I axis in acute liver injury. Two previous studies showed that application of GHRH antagonist attenuated oxidative stress in human cancer cells and aging cognitive deficiency mice, respectively [35, 36]. The inconsistency between the current study and these reports is probably from the differences between normal animal and cancer cell line, as well as the differences between the healthy and APAP-induced liver injury animals. Application of GHRH antagonist has been proven to be therapeutic in many cancer cell lines in which it attenuates inflammation, oxidative stress, and apoptosis. While in APAP-induced acute liver injury mice, pre-treatment with MZ-5-156 blocked the production of GHRH from the pituitary to reduce the circulating and hepatic GH levels, which could protect liver against acute liver injury [28].

In conclusion, inhibition of GHRH by using GHRH antagonist MZ-5-156 aggravated acute liver injury, oxidative stress, and inflammation induced by APAP intoxication. This effect was associated with reduced circulating levels of GH and IGF-I, as well as impaired JAK2/STAT5 signaling pathway. Thus, GHRH was important for the basal hepatic defense against druginduced acute liver injury.

\section{References}

1. Lee WM (1993) Acute liver failure. New Engl J Med 329:1862-1872.

2. Larson AM (2007) Acetaminophen hepatotoxicity. Clin Liver Dis 11:525-548.vi.

3. Dahlin DC, Miwa GT, Lu AY, Nelson SD (1984) N-acetyl-p-benzoquinone imine: a cytochrome P-450mediated oxidation product of acetaminophen. Proc Natl Acad Sci USA 81:1327-1331.

4. Beckett GJ, Chapman BJ, Dyson EH, Hayes JD (1985) Plasma glutathione S-transferase measurements after paracetamol overdose: evidence for early hepatocellular damage. Gut 26:26-31.

5. James LP, Mayeux PR, Hinson JA (2003) Acetaminophen-induced hepatotoxicity. Drug Metab Dispos 31:1499-1506.

6. Hinson JA, Roberts DW, James LP (2010) Mechanisms of acetaminophen-induced liver necrosis. Handb Exp Pharmacol 196:369-405.

7. Brand MD, Affourtit C, Esteves TC, Green K, Lambert AJ, Miwa S, Pakay JL, Parker N (2004) Mitochondrial superoxide: production, biological effects, and activation of uncoupling proteins. Free Radica Biol Med 37:755-767.

8. Sies H, de Groot H (1992) Role of reactive oxygen species in cell toxicity. Toxicol Lett 1992, 64-65:547-551.

9. Gaylinn BD (2002) Growth hormone releasing hormone receptor. Receptors Channels 8:155-162.

10. Barabutis N, Schally AV (2010) Growth hormone-releasing hormone: extrapituitary effects in physiology and pathology. Cell Cycle 9:4110-4116.

11. Schally AV, Varga JL (2006) Antagonists of growth hormone-releasing hormone in oncology. Comb Chem
High Throughput Screen 9:163-170.

12. Schally AV, Varga JL (1999) Antagonistic Analogs of Growth Hormone-releasing Hormone: New Potential Antitumor Agents. Trends Endocrinol Metab 10:383391.

13. Chatzistamou I, Schally AV, Varga JL, Groot K, Armatis P, Busto R, Halmos G (2001) Antagonists of growth hormone-releasing hormone and somatostatin analog RC-160 inhibit the growth of the OV-1063 human epithelial ovarian cancer cell line xenografted into nude mice. J Clin Endocrinol Metab 86:2144-2152.

14. Szepeshazi K, Schally AV, Groot K, Armatis P, Hebert F, Halmos G (2000) Antagonists of growth hormone-releasing hormone (GH-RH) inhibit in vivo proliferation of experimental pancreatic cancers and decrease IGF-II levels in tumours. Eur J Cancer 36:128-136.

15. Kovacs M, Kineman RD, Schally AV, Zarandi M, Groot K, Frohman LA (1997) Effects of antagonists of growth hormone-releasing hormone (GHRH) on GH and insulin-like growth factor I levels in transgenic mice overexpressing the human GHRH gene, an animal model of acromegaly. Endocrinology 138:4536-4542.

16. Kanashiro-Takeuchi RM, Takeuchi LM, Rick FG, Dulce $\mathrm{R}$, Treuer AV, Florea V, Rodrigues CO, Paulino EC, Hatzistergos KE, Selem SM, Gonzalez DR, Block NL, Schally AV, Hare JM (2012) Activation of growth hormone releasing hormone (GHRH) receptor stimulates cardiac reverse remodeling after myocardial infarction (MI). Proc Natl Acad Sci USA 109:559-563.

17. Bustin SA, Benes V, Garson JA, Hellemans J, Huggett J, Kubista M, Mueller R, Nolan T, Pfaffl MW, Shipley GL, et al. (2009) The MIQE guidelines: minimum infor- 
mation for publication of quantitative real-time PCR experiments. Clin Chem 55:611-622.

18. Argetsinger LS, Carter-Su C (1996) Mechanism of signaling by growth hormone receptor. Physiol Rev 76:1089-1107.

19. Csernus VJ, Schally AV, Kiaris H, Armatis P (1999) Inhibition of growth, production of insulin-like growth factor-II (IGF-II), and expression of IGF-II mRNA of human cancer cell lines by antagonistic analogs of growth hormone-releasing hormone in vitro. Proc Natl Acad Sci USA 96:3098-3103.

20. Sablina AA, Budanov AV, Ilyinskaya GV, Agapova LS, Kravchenko JE, Chumakov PM (2005) The antioxidant function of the p53 tumor suppressor. Nat Med 11:13061313.

21. Stangelberger A, Schally AV, Rick FG, Varga JL, Baker B, Zarandi M, Halmos G (2011) Inhibitory effects of antagonists of growth hormone releasing hormone on experimental prostate cancers are associated with upregulation of wild-type p53 and decrease in p21 and mutant p53 proteins. Prostate 72:555-565.

22. Kanashiro-Takeuchi RM, Tziomalos K, Takeuchi LM, Treuer AV, Lamirault G, Dulce R, Hurtado M, Song Y, Block NL, Rick F, et al. (2010) Cardioprotective effects of growth hormone-releasing hormone agonist after myocardial infarction. Proc Natl Acad Sci USA 107:2604-2609.

23. Wu X, Herndon DN, Wolf SE (2003) Growth hormone down-regulation of Interleukin-1beta and Interleukin-6 induced acute phase protein gene expression is associated with increased gene expression of suppressor of cytokine signal-3. Shock 19:314-320.

24. Johnson TS, O'Leary M, Justice SK, Maamra M, Zarkesh-Esfahani SH, Furlanetto R, Preedy VR, Hinds CJ, El Nahas AM, Ross RJ (2001) Differential expression of suppressors of cytokine signalling genes in response to nutrition and growth hormone in the septic rat. J Endocrinol 169:409-415.

25. Jeschke MG, Herndon DN, Wolf SE, DebRoy MA, Rai J, Lichtenbelt BJ, Barrow RE (1999) Recombinant human growth hormone alters acute phase reactant proteins, cytokine expression, and liver morphology in burned rats. J Surg Res 83:122-129.

26. Chrysopoulo MT, Jeschke MG, Ramirez RJ, Barrow RE, Herndon DN (1999) Growth hormone attenuates tumor necrosis factor alpha in burned children. Arch Surg 134:283-286.

27. Jeschke MG, Barrow RE, Herndon DN (2000) Recombinant human growth hormone treatment in pediatric burn patients and its role during the hepatic acute phase response. Crit Care Med 28:1578-1584.

28. An Y, Xiao YB (2007) Growth hormone prevents acute liver injury induced by cardiopulmonary bypass in a rat model. J Thorac Cardiov Sur 134:342-350.

29. Thirone AC, Carvalho CR, Saad MJ (2002) G120KPEG, a human GH antagonist, decreases GH signal transduction in the liver of mice. Mol Cell Endocrinol 192:65-74.

30. Yang N, Langenheim JF, Wang X, Jiang J, Chen WY, Frank SJ (2008) Activation of growth hormone receptors by growth hormone and growth hormone antagonist dimers: insights into receptor triggering. $\mathrm{Mol}$ Endocrinol 22:978-988.

31. Siejka A, Schally AV, Block NL, Barabutis N (2010) Antagonists of growth hormone-releasing hormone inhibit the proliferation of human benign prostatic hyperplasia cells. Prostate 70:1087-1093.

32. Saha JK, Xia J, Grondin JM, Engle SK, Jakubowski JA (2005) Acute hyperglycemia induced by ketamine/xylazine anesthesia in rats: mechanisms and implications for preclinical models. Exp Biol Med (Maywood) 230:777784.

33. Zaher H, Buters JT, Ward JM, Bruno MK, Lucas AM, Stern ST, Cohen SD, Gonzalez FJ (1998) Protection against acetaminophen toxicity in CYP1A2 and CYP2E1 double-null mice. Toxicol Appl Pharmacol 152:193-199.

34. Bai J, Cederbaum AI (2004) Adenovirus mediated overexpression of CYP2E1 increases sensitivity of HepG2 cells to acetaminophen induced cytotoxicity. Mol Cell Biochem 262:165-176.

35. Barabutis N, Schally AV (2008) Antioxidant activity of growth hormone-releasing hormone antagonists in LNCaP human prostate cancer line. Proc Natl Acad Sci USA 105:20470-20475.

36. Banks WA, Morley JE, Farr SA, Price TO, Ercal N, Vidaurre I, Schally AV (2010) Effects of a growth hormone-releasing hormone antagonist on telomerase activity, oxidative stress, longevity, and aging in mice. Proc Natl Acad Sci USA 107:22272-22277. 